\title{
DEVELOPMENT OF 3D CADASTRE IN NEW SOUTH WALES THROUGH P-PLAN LODGEMENT
}

\author{
Taha Masri; Dev Raj Paudyal \\ School of Civil Engineering and Surveying \\ University of Southern Queensland, Australia
}

Commission IV, WG IV/6

KEY WORDS: LandXML, Strata Plan, Digital Lodgement, 3D Cadastre

\begin{abstract}
:
With rapid growth of urban environments worldwide, there is an increasing need to develop more innovative and efficient land administration systems. In Australia, various jurisdictions are currently in the process of implementing 3D cadastre to support better land administration services to the wider community. The 'Cadastre 2034 Strategy' published by the Intergovernmental Committee on Surveying and Mapping (ICSM) for Australia in 2014 indicates that a digital cadastre will be implemented as part of that strategy. As part of development of 3D cadastre, State of New South Wales has used the ePlan model based on LandXML for digital lodgement and validation of cadastral plans. This initiative aims to replace PDF cadastral plans with the digital format of LandXML. However, with the introduction of LandXML as the chosen formats for digital cadastral plans in NSW, there has been a significantly low level of Strata Plan digital capture and submission in LandXML format by the surveying industry. The research aims to identify the main challenges and explore a suitable method to improve the adoption of the digital format for Strata Plan submission and development of 3D cadastre in NSW. In this research paper, a mixed method research approach has been used by integrating both qualitative and quantitative data. The primary data was collected using online questionnaires and surveys of different stakeholders from government and the private surveying industry. The data allowed for the assessment of the effectiveness and implications of the digital system currently maintained by the NSW LRS (Land Registry Services). A case study was used for the creation, validation and lodgement of an existing strata plan using LandXML format. This paper demonstrates that implementation of 3D digital cadastral plans needs to be more structured in order to satisfy all stakeholders involved. More investment into the representation of complex 3D geometric models and classification for validation will improve the uptake by surveyors. The paper concludes with a discussion on the implications of the proposed strata plan implementation strategy and proposes future research within the topic of strata plan validation in NSW, Australia.
\end{abstract}

\section{BACKGROUND}

\subsection{Introduction}

Many cadastres have started to show 3D information on cadastral plans, such as isometric views, vertical profiles, or textual information. However, real 3D solutions (i.e., implementing interactive 3D visualisations) barely exist (van Oosterom \& Dimopoulou, 2019). The current arrangement of 2D digital cadastre represents only 2D parcels and omits an array of property objects that are vertically located, such as apartments, tunnels, underground shopping centres, carparks and utility networks. Urban built environments are increasingly becoming more spatially complex (Shojaei et al., 2018). One of the expensive phases of the implementation of a 3D cadastre is the 3D data capture. There are two options for 3D data capture; surveying in $3 \mathrm{D}$, or using data sources such as construction and design models, and the reconstruction of legal volumes from design data.

The NSW Land Registry Services (LRS) operates the NSW land titles registry on behalf of the NSW Government under a 35-year concession that took effect on 1 July 2017 (NSW LRS, 2021). LRS is responsible for the land titling and registration of survey plans in NSW. The LRS ensures reliability of boundary definitions in survey plans and creates new titles for parcels. It also maintains the integrity of the cadastre (Deal, 2017). ePlan is an electronic plan lodgement and validation system developed by the LRS, which has been adopted since 2010 in NSW as a digital cadastral data initiative to replace 2D PDF and TIFF survey plans into useable LandXML format (NSW LRS, 2021). This portal is used as the main lodgement platform for digital and TIFF files followed by hardcopy lodgement over the counter. The NSW Land Registry Services is transition to PDF lodgement in ePlan. NSW LRS registered 1829 strata plans in 2017-2018, 1762 strata plans in 2018-2019 and 1764 strata plans in 2019-2020. As of 31 January 2021, 2412 LandXML plans have been lodged creating 44,626 new lots (NSW LRS, 2021).

The current 3D based method of representation is costly and time-consuming. The integrity of the cadastral system reflects the quality of the cadastral data inputs. In order to maintain the 3D cadastre, the cadastral data must be validated in each of the steps. This validation will be the basis on which to define the extent of ownership. This makes it more difficult as more complex strata buildings ownership rights are represented on paper in 2D plans (Atazadeh et al., 2017).

Only minor research has been conducted into the capturing, validating, and visualising of 3D digital plans in NSW. The issue is that the current digital cadastral database shows only land ownership at ground level, with no indication of what is below or above the surface. This has created the need to capture 3D strata plans to integrate into the current digital cadastral database so that different stakeholders, such as surveyors, spatial professionals, local government, and utilities providers will benefit (Forman, Harding, 2017). Although the ePlan portal created by LRS has been operational in NSW since 2010, only five per cent of plans lodged are in digital format (NSW LRS, 
2021). Moreover, only one strata plan has been registered in NSW in LandXML format, which represents less than one per cent of the total number of plans registered (Daniel, 2020). This has created serious concern for the LRS to develop 3D cadastre and a need to identify the issues associated with current ePlan implementation in NSW. Given the very low adoption rate of digital plans by surveyors, this research paper proposes to explore the current trends and identify the challenges different stakeholders face with the uptake of 3D data capture and validation. There has been very limited research into the current arrangements of 3D digital cadastral plan implementation and its contribution to the digital cadastral database. The current cadastral system will need to cater for the future digital cadastral system as the strategy for "Cadastre 2034" (ICSM, 2015).

\subsection{Statement of the Purpose}

While the NSW LRS introduced submission of 3D cadastral plans in 2010, the number of strata plans being lodged in digital format is less than one per cent. This significantly low uptake of digital plan creation by surveyors has also been noticed in other jurisdictions of Australia. The research studies carried out by Ashghari (2020), Grosvenor Public Sector Advisory (2019), KarKi et al. (2011) and Olfat (2017) suggested that there is need for appropriate 3D digital cadastral data capture and validation method to develop 3D Cadastre in Australia that can support the registration of legal spaces in $3 \mathrm{D}$. Although the new software development and validation processes have been implemented by the LRS, many stakeholders, particularly surveyors, have not adopted the chosen LandXML file format. The focus of this research paper is to investigate the potential problems associated with validation and rendering through to lodgement. There is currently a research gap regarding registration of a digital strata plan in NSW and the suitability of LandXML as a file format. This research project explored this knowledge gap. The primary objectives of this research paper are to firstly, investigate the very low uptake of digital plans by the surveying industry, and secondly, to examine the current lodgement process for 3D digital cadastral plans and associated validation challenges in NSW.

This paper comprises a current review of recent research regarding 3D Cadastre, and a discussion of the currently existing ePlan system and examination process in NSW. A framework developed for the objectives has been outlined and finally, a discussion and final remarks are made regarding the uptake and development of 3D cadastral plans in NSW.

\section{LITERATURE REVIEW}

\subsection{Relevant Studies Outlining the Validation of 3D Cadastral Plans}

3D plan creation has been investigated by various experts in the field to some degree. Karki et al. (2011) have investigated and supported the ePlan protocol for 3D objects, while Cumerford (2010) suggested that ePlan is able to support 3D survey plans including strata, despite expressing several reservations with the validation of such 3D objects. The method Cumerford (2010) used during his 105 research was to reference the faces of the parcel, however, this research intends to test the ePlan validation and rendering using Landxml format, which uses CGpoints rather than reference faces. Shojaei et al (2017) attempted to establish validation rules that work with the ePlan Protocol, which included a "plan lodgement and examination system in Australia, for checking 3D objects". However, due to the different validation rules and cadastral systems, this classification was not possible. Asghari et al (2019) reasoned that "principles and validation rules need to be developed based on a structured framework following the regulations and standards of a cadastral system". This means that every jurisdiction will need to consider creating its own compatible rules that adhere to jurisdictional cadastral law. A study by Atazadeh et al. (2016) suggested that 3D validation models used for validation can be either physical, legal or combined. The research shows that most of the studies have focused on the legal side rather than a combined method. The validation used in NSW does not examine the administration sheets accompanying the plan.

\subsection{NSW Strata Title and Strata Plan}

Strata title is a form of ownership devised for multi-level apartment blocks and horizontal subdivisions with shared areas. The 'strata' part of the term refers to apartments being on different levels, or 'strata' (ICSM, 2020). Strata Title Schemes are composed of individual lots and common property, as illustrated in Figure 1. The introduction of the Strata Titles Act 1961 in NSW, and similar acts in other states, made possible the volumetric subdivision of a building into individual lots and common property. Since then, the legislation has been amended and updated to the Strata Schemes (Freehold Development) Regulation 2015 (LRS, 2020). The strata title has been adopted in many different countries, including Singapore, Malaysia, and Canada. The Strata Title Act 1961 was developed in order to improve the current company title system. Under this type of title, a proprietor owns shares in a limited company that holds the title for the land. The company then allows homeowners to occupy the building. Company title still exists in NSW, where strata subdivision is not consented by local government.

A strata plan is the subdivision of a building into different lots and common property (NSW LRS, 2021) and must be prepared by a registered cadastral surveyor in NSW and other jurisdictions in Australia. The key difference between a regular land subdivision and a strata subdivision is that the boundaries are formed by the structure of the building itself and are not dimensioned on the final plans. There is an exception when there is no structure; for example, a carpark spot marked with line marking. In this case, it will be dimensioned from an existing structure to enable reinstatement in the future. The area shown on the strata plan is approximate. The remaining parts of the structures that are not allocated to a lot are common property noted as $\mathrm{CP}$ on that plan. The keeping of the common property falls on the owners' corporation. According to schedule 2 of the Strata Schemes Development Act 2015, all unit entitlements need to be prepared by a qualified valuer. The unit entitlement accompanies the strata plan administration sheet. The unit entitlements are calculated based on the value of the unit, so the maintenance cost is distributed fairly. The strata scheme is used on the subdivision of multi-storey buildings and two-unit duplexes. See Figure 1 for an example of a location plan which shows the cadastral boundary in relation to the building with appropriate offset measurements. Note no bearings are to be used on a location plan, only distances. It also shows the type and size of the building and the adjoining cadastral information. The floor plan shows the lot in a thick line based on a structure and will have vinculum to other parts of that lot that are part of the corresponding lot, e.g. garage or balcony. 


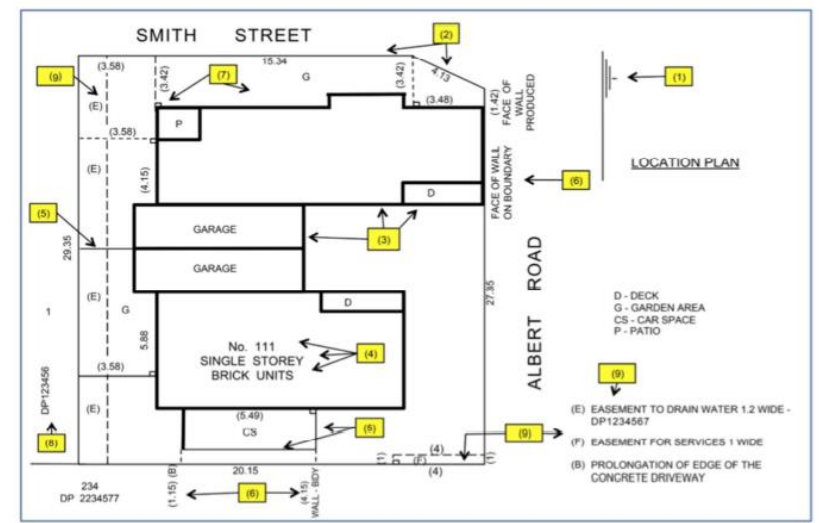

Figure 1: Location Plan (NSW LRS, 2021)

In NSW, the Office of the Registrar General is responsible for the registration and administration of survey plans (ElKiki,2017). The Registrar General's Guidelines provide directions to surveyors in the preparation of strata scheme plans. The NSW LRS has a published Plan Preparation Guide Strata Plans which was last updated in 2019 (NSW LRS,2021). This document includes examples of effective and poor plans. It does not mention how to prepare the plan from the field or office, so it is up to the surveyor to use his or her discretion when measuring and compiling the strata plan to meet the requirements of the Act and Regulations when lodging a plan in TIFF or PDF format. The LRS has developed a document entitled "the NSW Land XML Recipe (v9.1)" to assist in the construction of a digital plan suitable for lodgement (NSW LRS,2021). This version was last updated in June 2019. The surveyor must still lodge a TIFF copy, with the digital plan as the online rendering component in the portal still under development. The NSW Land Registry Services is transition to PDF lodgement in ePlan.

\subsection{Traditional Method of Lodging Survey Plans in NSW}

After field and office work has been completed, the surveyor or lodging party submits a hard copy of the plan and administration sheets at the NSW LRS Office or electronic through the ePlan Portal (Figure 2). After the submission, the plan checks by the LRS Plan Examiner for accuracy and completeness. This process is done manually. If the plan passes, the digital plan will be stored as a TIFF image. If it does not pass, a requisition will be raised for the surveyor to amend the plan for further examination. The TIFF image will be then stored in the database for future use. This is now being replaced with digital lodgement of LandXML files (EI-Kiki, 2017). During 2019-2020 hard copy and TIFF plan lodgement represented 95 per cent of all plans lodged in NSW with only five per cent being digital (NSW LRS, 2021).

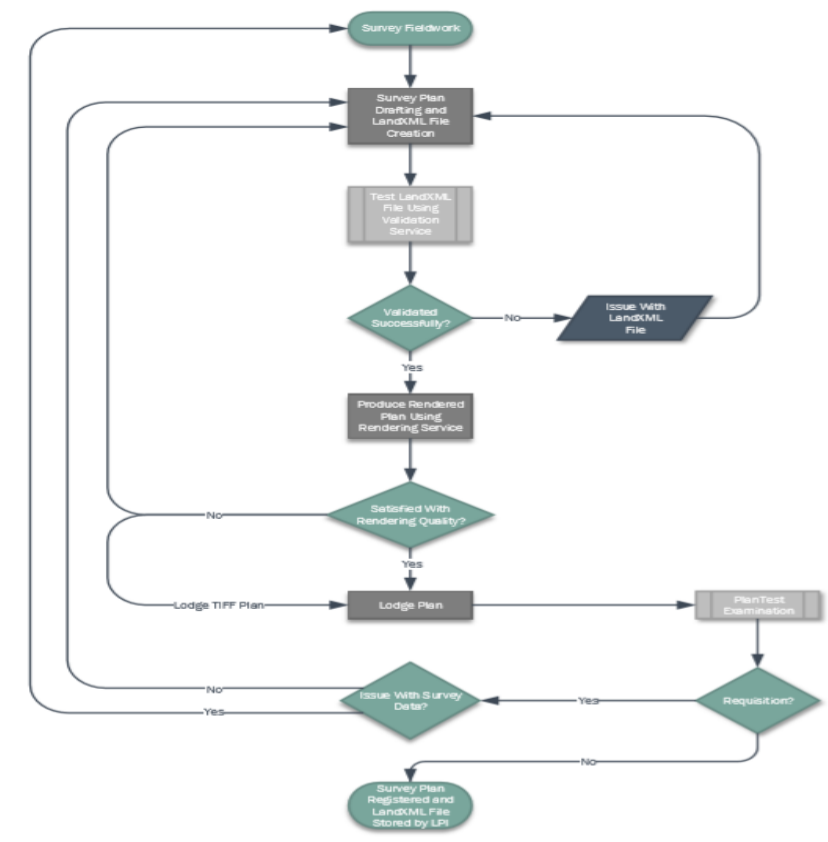

Figure 2: Method of Lodgement (EI-Kiki, 2017)

\section{4 e-Plan Lodgement Portal}

The NSW LRS has made available digital plan lodgement through their online portal for users with level 3 ePlan access (NSW LRS, 2021); the requirements for lodgement include administration sheets with signatures and certifications as a TIFF format. The LandXML file is submitted as part of the lodgement bundle with administration sheets and TIFF files (NSW LRS, 2021). This service saves time as it can be lodged from anywhere in the world. Most importantly it helps to avoid requisitions, as errors will be detected early in the validation process.

The validation service helps surveyors to check their plans against 100 business and survey regulations and rules. This service allows the surveyor to minimise requisitions that delay registration (NSW LRS, 2021).

The rendering service allows surveyors to create an image from a LandXML file. This service helps to visualise the plan. Up to now, the current arrangement is to lodge a TIFF image of the plan as the system at the LRS cannot produce a quality image (NSW LRS, 2021).

The final stage after the validation and rendering is the LRS examination. The LRS use the "Plan Test" software. The software automates the checking process, as this would traditionally be done manually. Part of the check is the bearing and distances of each line and miscloses for closed polygons.

\section{RESEARCH METHODOLOGY}

The mixed method approach has been used as it utilises qualitative and quantitative research methods to collect both primary and secondary data. According to Mack (2005) there are two main advantages of the qualitative method. One of the advantages is the use of open-ended questions. This gives the respondents the opportunity to use their own words. The other advantage is that the researcher can help trigger responses by adding probes such as how and why. This method will be 
adopted as it gives the researcher a wide variety of methods, which include face-face interviews, and focus groups discussion. This method is suitable as the interaction between the interviewer and interviewee is concurrent with no time delay. It allows for a personal interaction with surveyors in the comfort of their office. Figure 3 demonstrates the research framework that has been developed for this project.

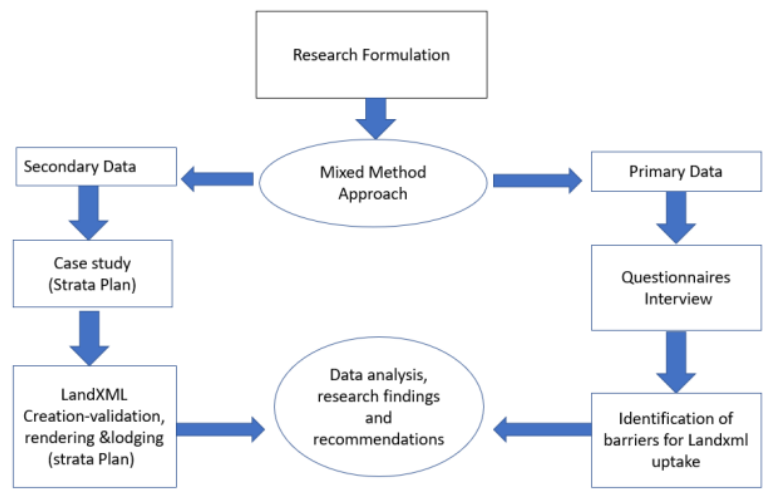

Figure 3: Research Framework

\subsection{Data Collection and Analysis}

Online survey questionnaire was shared with 52 participants, resulting in a response rate of 82 per cent. Most of the respondents were surveyors from private firms, while the others were from various government organisations. The survey was conducted between June and July 2020. A total of 42 responses were obtained through the online questionnaire and interviews. The online questionnaire was conducted using an online platform and the data then exported to MS Excel for further statistical analysis. This method limits any possibility of errors during the transcription of results. The data was appraised for quality assurance before exporting to MS Excel. The survey was conducted with different stakeholders involved in the end-toend process of creation, review and use of digital survey plans. Each member of the stakeholder group had a knowledgeable understanding of different elements involved in the creation, review, and end-to-end use of survey plans. The objective of the questionnaire was to determine the low acceptance of and opportunities that exist for digital survey plans. Limitations encountered in this research included complicated technical coding issues and the lack of a detailed cost benefit analysis. These themes will be of benefit to develop further solutions and recommendations for the successful implementation of digital plans.

The three key areas for understanding the factors contributing to the low uptake are provided in the following Table 1.

\begin{tabular}{|c|c|}
\hline Themes & Contributing factors \\
\hline Outcomes sought & $\begin{array}{c}\text { Plan creation, spatial cadastral } \\
\text { database, registration. }\end{array}$ \\
\hline $\begin{array}{c}\text { Opportunities for } \\
\text { digital change }\end{array}$ & $\begin{array}{c}\text { Issues, benefits, quality assurance, } \\
\text { incentives, attitudes, transparency, } \\
\text { reduction in requisition. }\end{array}$ \\
\hline $\begin{array}{c}\text { Barriers for adoption } \\
\text { of digital plans }\end{array}$ & $\begin{array}{c}\text { Consultation with stakeholders, } \\
\text { education on benefits, cost of } \\
\text { change. }\end{array}$ \\
\hline
\end{tabular}

Table 1: Key Themes for Low Adoption of LandXML

\section{RESULTS}

\subsection{Primary Data}

The primary data were collected from online survey and interview. The results from questionnaire and interview are presented below. The purpose of primary data collection was to identify the barriers for LandXML uptakes.

\subsubsection{Outputs Sought from Digitisation}

In respect to the outcomes sought from the digitisation of plans, 81 per cent of respondents agreed reduction in requisition is a key factor for adoption.

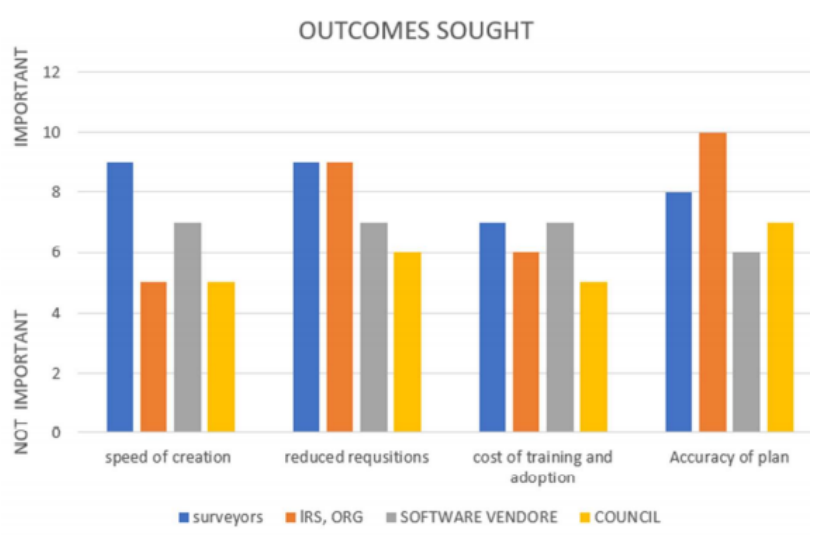

Figure 4: Outcomes Sought from Digitisation

The largest respondent group in the survey was surveyors, at 90 per cent. It was understood that their main objective from the end-to-end process of producing plans was maintaining the integrity of the cadastre and satisfying clients' needs. On the other hand, the other respondents from the LRS and ORG, while also maintaining the integrity of the cadastre, their main focus is on the enhancement and development of the lodgement and registration of plans. However, another area of importance was to deliver greater advancements to the profession and maintain its professional ethics and standards. Surveyors indicated that cost was very important in the change, while government agency maintained it was neutral. This is expected, as surveyors must compete for maximum profit.

More than 70 per cent of respondents indicated that they have had less than one year's of experience in the use of LandXML.

\subsubsection{Opportunities for Digital Change}

As illustrated in Figure 5, 90 per cent of the respondents to this question were surveyors, as they are mainly involved with the creation of the strata plan. 80 per cent of these respondents indicated that after field measurements the processing was done using a surveying software and exported into a drafting software usually AutoCAD drawing file (.DWG) format, while 20 per cent did the drafting within the surveying software. Further analysis shows that surveyors are willing to pass the drafting to the draftsperson for completeness and timesaving. 


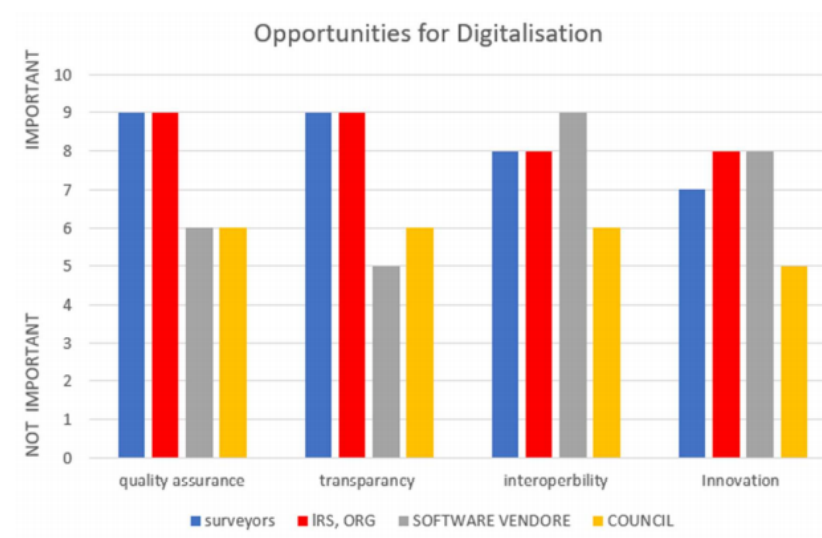

Figure 5: Opportunities for Digitisation

\subsubsection{Barriers for Adoption of Digital Plans}

The majority of surveyors (90 per cent) had concern about the quality of the plan. The main concern was the quality of rendering. This problem is also highlighted by Shojaei et.al (2018), where the surveyors consulted estimated the extra time to make the LandXML file was up to double the time. However, the NSW LRS has significant interest in change as it has embarked on a back-capture project. Councils' willingness to change was reserved as they had their own internal software and changing needed to be worthwhile as they also capture GIS data. Therefore, interoperability is paramount for any future change (As illustrated in the Figure 6).

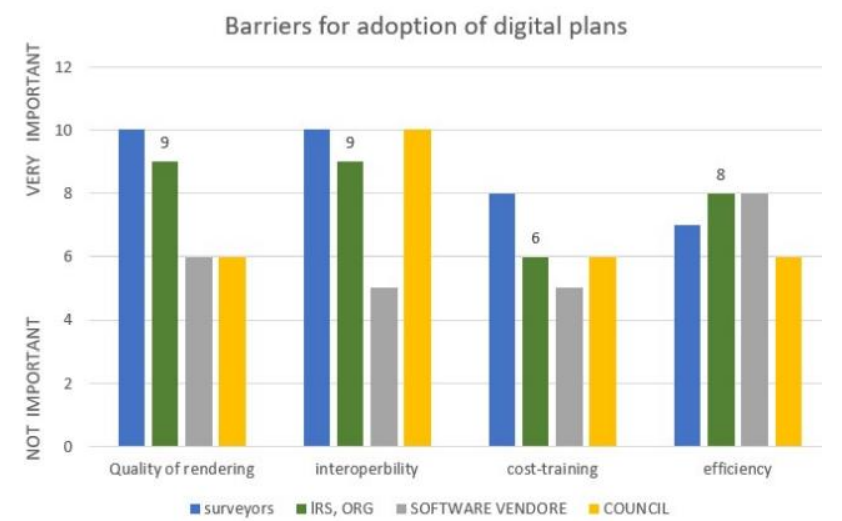

Figure 6: Barriers for Adoption of Digital Plans

\subsection{Secondary Data}

The aim of this case study was to take a representative case of an existing strata plan and turn it into a LandXML file to assess the current digital strata plan rendering and validation through to submission using the NSW LRS portal. The representative case is a four-lot strata plan. Figure 7 shows a location plan of the strata plan on TIFF format.

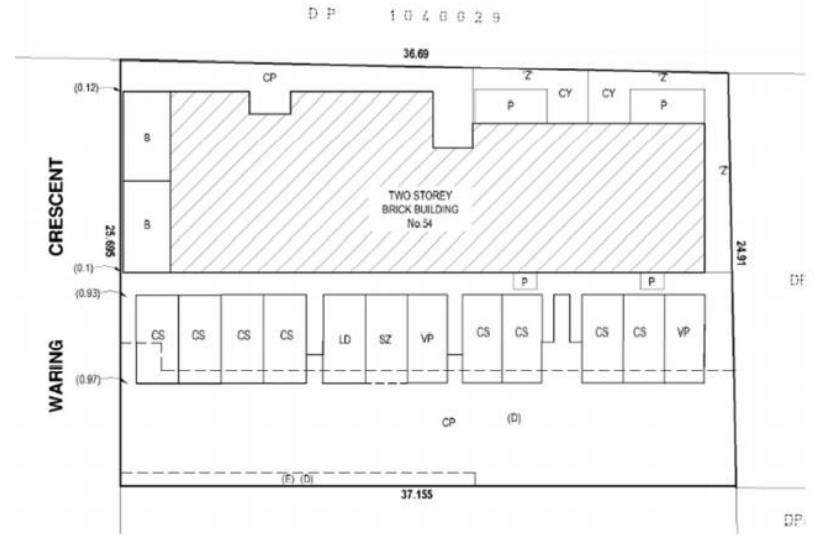

Figure 7: Strata Plan TIFF Format

The rules for plan validation have grouped into two parts as illustrated in the Table 2 below. The compliance parameter are identified and listed.

\begin{tabular}{|l|l|}
\hline Validation Rules & Compliance \\
\hline Administrative & Existing plan or creation \\
\cline { 2 - 2 } & Plan format requirement \\
\cline { 2 - 2 } & Lot-building numbering \\
\cline { 2 - 2 } & Common property location \\
\hline Geometry & Any encroachments \\
\cline { 2 - 2 } & Total areas and parts \\
\cline { 2 - 2 } & Confirmation of voids, area \\
\cline { 2 - 2 } & Extent of the lots, and location \\
\hline
\end{tabular}

Table 2: Validation Table

The plan was created into LandXML format using stringer ePlan software. After installing Stringer ePlan software, a ribbon was added to the $\mathrm{CAD}$ package. The $\mathrm{CAD}$ drawing was opened and completed the setting (project information). The parcels, and points including the segments were enumerated and annotations were added. The output was reviewed and exported into LandXML file. The created LandXML file was uploaded in the portal for automated checking against the validation rules in the NSW Schema. The portal automatically checked and returned a file, as illustrated in the Figure 8. 


\begin{tabular}{|c|c|c|c|c|}
\hline \multicolumn{2}{|c|}{$\begin{array}{l}\text { Validation P } \\
\text { File Name }\end{array}$} & $\begin{array}{l}\text { Rejected } \\
\text { Experiment 3.xml }\end{array}$ & & \multirow[b]{2}{*}{ Error $\mathbb{A}$} \\
\hline 표 & Bule: & Bule Description: & Status: & \\
\hline & o & Schema check & Passed & \\
\hline & 1 & Plan purpose & Passod & \\
\hline & 2 & Plan give eftect to purpose & Passed & \\
\hline & 3 & Lot numbering & Passod & \\
\hline & 4 & Valid secondary parcels & Passod & \\
\hline & 5 & Parcel attributes & Passod & \\
\hline & 6 & Vald parish & Passed & \\
\hline & 7 & Vald County & Passod & \\
\hline & $\mathbf{a}$ & Vald LGA & Passed & \\
\hline & 9 & Vald Locality & Passod & \\
\hline & 10 & Valid Aroas & Passod & \\
\hline & 11 & Multipart lot aroas & Passod & \\
\hline & 12 & New lot area shown & Passod & \\
\hline & 13 & Parcel overlaps & Passod & \\
\hline & 14 & Multipart lot attributes & Nothoplicabie & \\
\hline & 15 & Parcel topology & Passed & \\
\hline & 16 & Maclose & Passed & \\
\hline & 17 & Line attribustes & Passed & \\
\hline & 18 & Valid Instrument point & Passed & \\
\hline & 19 & All points used & Passed & \\
\hline & 20 & RMPMM dimensions & Passed & \\
\hline & 21 & SCIMS Date vs Survey Date & Passed & \\
\hline & 22 & scims swetch & Passed & \\
\hline & 23 & Oftset boundary mark & Passed & \\
\hline & 24 & unmarked boundary & Passed & \\
\hline
\end{tabular}

Figure 8: Validation Results Table

The different rules have all been met and satisfied by the automatic checking. This ensures less human error when manual checks were done and accelerated the checking process.
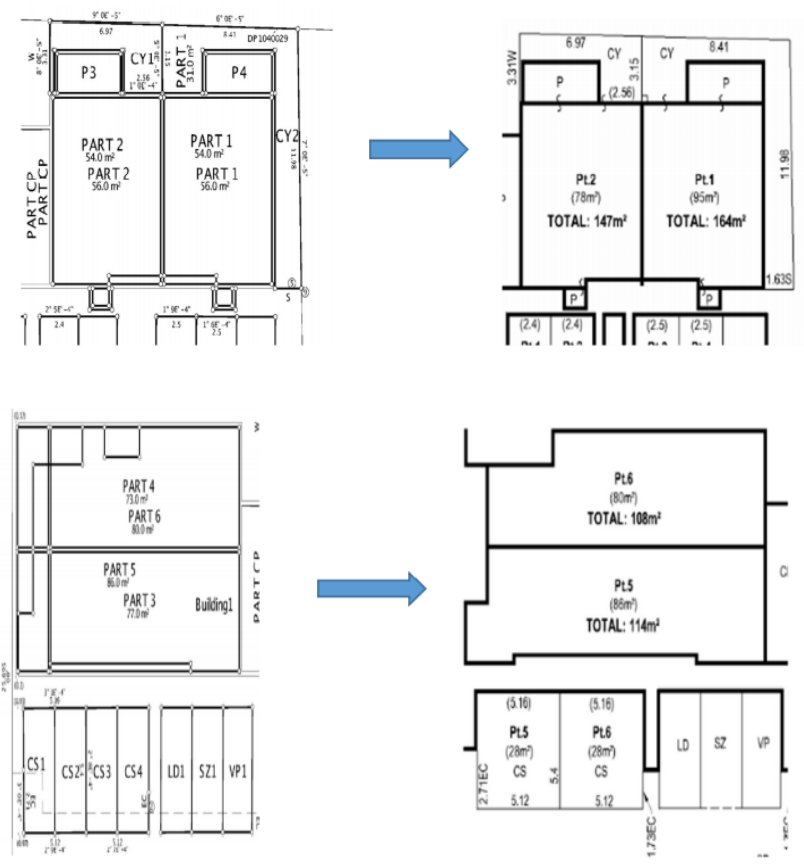

Figure 9 illustrated the quality of the rendering produced by the NSW LRS ePlan Portal. The rendering was of poor quality and not meeting the standards. Part of the floor plan are shown in the Figures for comparison. The Lot number in the rendering appears twice. The structural line boundaries are shown with circles at the end. The line thickness was of concern and the portal did not display thick and thin lines as this might create a confusion between structure and non-structure boundary e.g. line marking for a car space belonging to a unit.

The same plan was then produced as a TIFF format to comply with the drafting standards of NSW. The portal did not distinguish between thick and thin line for strata boundaries. As per NSW drafting standards, thick line which represents line boundaries and structural boundaries. These visualisation problems with the portal have caused resistance for adoption from the surveying industry.

The results of the rendering have proven to be not meeting the NSW 2020 Schema standards. As the ePlan portal for rendering is still in prototype it cannot efficiently render quality strata plans that are of suitable for lodgement to the NSW LRS portal. Feedback from surveyors indicated that this lack of quality presentation has resulted in a negative attitude towards the uptake by surveyors. The wasted time in correcting and redrawing the file in TIFF format was creating an inconvenience and resistance as per feedback and experiment in the secondary data.

\section{DISCUSSION AND CONCLUSION}

The NSW LRS has been accepting LandXML files since 2010 , however, it received its first strata plan in 2019. The issue related to low acceptance of digital strata plan and implementation of a fully functioning 3D cadastre was investigated. In addition, this paper examines the current lodgement process for 3D digital cadastral plans and associated validation challenges in NSW. The mixed method approach involved different end-to-end stakeholder's attitudes towards the digitisation of plans. It is evident that an efficient validation service and a reduction in plan requisition was of benefit to all stakeholders.

Industry engagement is imperative in technical solutions with regard to the software and testing, with solutions being tested by all stakeholders. The ePlan portal for rendering is still in prototype and it cannot efficiently render quality strata plans that of suitable for lodgement to the NSW LRS. Improving the rendering quality will be a condition to improve the uptake of digital plans by the surveying industry in NSW. Industry engagement and inputs from stakeholders is important when the ePlan portal will be improved. Constant review of the current methods will not only be of great benefit locally but within different jurisdictions. The automated validation, which is one of the objectives of Cadastre 2034, has been of significant benefit during the implementation. Additionally, the rendering quality, missing and obscured data will need to be rectified in order to establish more significant and robust 3D digital cadastral plans in NSW.

Figure 9: Land XML Rendering and TIFF Images 


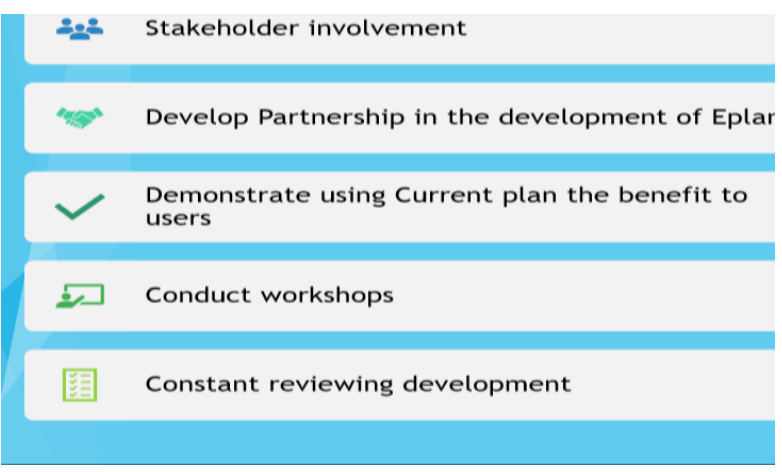

Figure 10: Strategy to Improve Uptake

Figure 10 illustrates the five-point strategy to improve the uptake. A strategy that will help with the uptake of digital plans includes greater involvement of end-to-end users in the development and testing of the current system. This partnership in development will give valuable feedback to ePlan for the continued refinement of their system. As per surveyors' feedback, they want to see the benefit to users. The investment in the digital plan must be road mapped with clear milestones. Developing workshops for surveyors will help encourage learning in the creation of LandXML files. Industry has shown that obtaining such skills is very limited and expensive. This development will allow the surveying industry to plan ahead and prepare for the adoption and submission of digital plans. The survey notations and occupations that are not included in the rendering are of concern as this information is vital in the redefinition of any plan in the future. An enhancement tool needs to be developed to help with the visualisation of plans and functionality, as under the current arrangement surveyors can spend long hours or days for drafting. This tool will save time as Victoria is developing an enhancement tool to help with visualisation (Olfat, 2018). This research has become more relevant to the surveying industry as the NSW LRS announced in August 2020 that it has captured more than 600,000 plans into LandXML with the intention of capturing 800,000 by 2020 (NSW LRS, 2021). This brings great certainty around the direction of NSW in its investment in LandXML.

This research paper has provided an insight from stakeholders on the adoption of a 3D cadastral plans, specifically for NSW. This paper examines the current lodgement process for 3D digital cadastral plans and associated validation challenges in NSW. A questionnaire and interview were completed and outlined the concerns of the different stakeholders involved in the end-to-end creation of strata plans. The study also used a case study to examine the rendering tool that was problematic and evaluated it according to the drafting standards of NSW. The study also outlined strategies that will increase the adoption of digital plans. These strategies will contribute to the development of a roadmap for the 3D research community in realising the Cadastre 2034 strategy. This research had limitations regarding the number of stakeholders and their experience with LandXML, while the case study involved only a basic strata plan. Further research is recommended into the capability of using the same validation rules across different jurisdiction, not only in NSW, in addition to the rendering of curved buildings and the quality of LandXML in the production of such plans. Future work on the representation of occupations and structures on rendered plans will be of great benefit to the development and adoption of this digital system.

\section{ACKNOWLEDGEMENTS}

We thank The Institution of Surveyors NSW/NSW Surveyors and USQ Human Research Ethics Committee for their support to complete this research project.

\section{REFERENCES}

Asghari, A., Kalantari, M., and Rajabifard, A., 2020. A Structured Framework for 3D Cadastral Data Validation: A Case Study for Victoria, Australia. Land Use Policy, Vol. 98 https://doi.org/10.1016/j.landusepol.2019.104359.

Atazadeh, B., Kalantari, M. and Rajabifard, A., 2016. Comparing Three Types of BIM-based Models for Managing 3D Ownership Interests in Multi-level Buildings, 5th International FIG 3D Cadastre Workshop 18-20 October 2016, Athens, Greece.

Atazadeh, B., Kalantari, M., Rajabifard, A., Ho, S., \& Ngo, T., 2016. Building Information Modelling for High-rise Land Administration. Journal Transactions in GIS 2016, 21, 91 - 113.

Ates-Aydar, S., Stoter, J., Ledoux, H., Ozbek, E. D., \& Yomraliogly, T., 2016. Establishing a National 3D Geo-data Model for Building Data Compliant to CityGML: Case of Turkey,In International Archives of the Photogrammetry, Remote Sensing and Spatial Information Sciences (Vol. 41-B2, pp. 79-86). https://doi.org/10.5194/isprs-archives-XLI-B2-792016.

Baran, M., 2010. Teaching Multi-Methodology Research Courses to Doctoral Students, International Journal for Multiple Research Approaches, Vol. 4, No. 1, 1927, DOI: 10.5172/mra.2010.4.1.019

Bevin, T., 1999. Cadastre 2014 Reforms in New Zealand. In Proceedings of the FIG Commission VII, Bay of Islands, New Zealand, 9-15 October 1999.

Choi, H. and Deal, M., 2019. NSW LandXML Recipe Document: Specifications for Preparation of Deposited Plans and Strata Plans in LandXML format for lodgment at NSW Land Registry Services, NSW Land Registry Services

Crews, N., 2006. LandXML.org 2006 - Presentations, Available: LandXML.org, accessed 04 April 2021.

El-Kiki, A., 2017. Software Ingestion of LandXML Files, Undergraduate Thesis, University of New South Wales, Australia.

EI-Kiki, A., 2020. 10 January 2020 Phone call with Office of Registrar General (Graduate Surveyor).

Griffin, D., 2020. May 2020 Email correspondence (Digital Plan Examination Team Leader).

Groger, G. and Plumer, L., 2011. How to Achieve Consistency for 3D City Models, GeoInformatica 15, 137-165. https://doi.org/10.1007/s10707-009-0091-6.

Grosvenor Public Sector Advisory, 2019. NSW DCS Digital Survey Plans Review, viewed 04 February 2021, <https://www.registrargeneral.nsw.gov.au/_data/assets/pdf_fil e/0010/603595/Grosvenor-Digital-Survey-Plans-Review-FinalReport.pdf $>$. 
Haanen, A., and Gulliver, T., 2018. A Vision for a Fully Digital Cadastral Survey System. In Proceedings of the FIG Congress 2018 Embracing Our Smart World Where the Continents Connect: Enhancing the Geospatial Maturity of Societies, Istanbul, Turkey, 6 - 11 May 2018.

Hancock, R.J., 2015. An Investigation into LandXML for Implementation of 3D Cadastre in eSurvey; Undergraduate Thesis, University of Southern Queensland, Australia.

Ho, S., and Rajabifard, A., 2016. Towards 3D-enabled Urban Land Administration: Strategic Lessons from the BIM Initiative in Singapore, Land Use Policy 57, 1 - 10.

ICSM, n.d., Strata Title [online], viewed 05 February 2021, $<$ https://www.icsm.gov.au/education/fundamentals-landownership-land-boundaries-and-surveying/land-and-landownership/systems>.

Kalantari, M., Rajabifard, A., Wallace, J., and Williamson, I., 2005. 'An Interoperability Toolkit for E-Land Administration', Paper Presented to Expert Group Meeting on Incorporating Sustainable Development Objectives into ICT Enabled Land Administration Systems, 9-11 November 2005, Melbourne, Australia.

Karki, S., Thomspon, R., McDougall, K., Cumerford, N. \& van Oosterom, P., 2011. ISO Land Administration Domain Model and LandXML in the Development of Digital Survey Plan Lodgement for 3D Cadastre in Australia, International Workshop on 3D Cadastres, 16-18 November 2011, Delft, the Netherlands.

Kolbe, T. H., 2009. Representing and Exchanging 3D City Models with CityGML. 3D Geo-Information Sciences. Lee J, Zlatanova S (Eds). Springer, Berlin.

Mack, N., 2005. Qualitative Research Methods: A Data Collector's Field Guide, Family Health International, North Carolina 27709 USA, Viewed 04 February 2021, <http://repository.umpwr.ac.id:8080/bitstream/handle/12345678 9/3721/Qualitative\%20Research\%20Methods_Mack\%20et\%20 al_05.pdf?sequence $=1>$

Myers, M. D., 1997. Qualitative Research in Information Systems. MIS Quarterly 21, 241-242.

NSW LRS Digital Plans (Online). Viewed 04 February 2021, <https://www.nswlrs.com.au/Digital-Plans>.

NSW LRS Lodgement (Online), n.d., Viewed 04 February 2021, <https://rg-guidelines.nswlrs.com.au/edealings/elodgment>.

NSW LRS, 2021. Strata Plan Preparation Guide, NSW Land Registry Services.

Olfat, H., Shojaei, D. and Briffa, M., 2016. The Victorian Digital Cadastre: Challenges and Investigations. 3rd Annual Conference of Research@Locate, 12-14 April, 2016, Melbourne, Australia.

Olfat, H., Shojaei, D., Briffa, M. and Rajabifard, A., 2017. The Current Status and Ongoing Investigations of 2D and 3D Digital Cadastre (ePlan) in Victoria, Australia.10th International Symposium on Digital Earth and Locate 17, 3-6 April 2017.
Shojaei, D., Olfat, H., Rajabifard, A. and Briffa, M., 2018. Design and Development of a 3D Digital Cadastre Visualisation Prototype, ISPRS International Journal of Geo-Information, vol. 7, no. 10, p. 384, viewed 04 February, 2021, <http://dx.doi.org/10.3390/ijgi7100384>.

Soon, K.H., Tan, D., and Khoo, V., 2016. Initial Design to Develop a Cadastral System that Supports Digital Cadastre, 3D and Provenance for Singapore. In Proceedings of the 5th International FIG Workshop on 3D Cadastre, Athens, Greece, 18- 20, October 2016.

Spatial Services (online), viewed 04 February 2021, <https://www.spatial.nsw.gov.au/what_we_do/projects/survey_ plan_digitisation_project>.

Thomas, R., 2003. Blending Qualitative and Quantitative Research Methods in Thesis and Dissertations, Second edition, Corwin Press, Thousand Oaks, California.

van Oosterom, P. and Dimopoulou, E., 2019. Introduction to the Special Issue: Research and Development Progress in 3D Cadastral Systems, Printed Edition of the Special Issue Published in International Journal of Geo-Information.

Wady, V., 2009. An Investigation of Land and Property Information (NSW) Proposed E-Plan Process of Digital Survey Plan Lodgement in LandXML Format. 2009, viewed 04 February 2021, <https://eprints.usq.edu.au/8534/1/ Wady_2009.pdf>. 